\title{
EDUCAÇÃO BILÍNGUE PARA SURDOS/AS: UM ESTUDO COMPARATIVO DA ESCOLA BILÍNGUE E DO ATENDIMENTO EDUCACIONAL ESPECIALIZADO (AEE) NA ESCOLA INCLUSIVA
}

\author{
EDUCACIÓN BILÍNGUE PARA SORDOS: UN ESTUDIO COMPARATIVO DE \\ LA ESCUELA BILÍNGUE Y DEL ATENDIMIENTO EDUCACIONAL \\ ESPECIALIZADO (AEE) EN LA ESCUELA INCLUSIVA
}

\author{
BILINGUAL EDUCATION FOR THE DEAF: A COMPARATIVE STUDY OF \\ BILINGUAL SCHOOLS AND SPECIALIZED EDUCATIONAL ATTENDANCE IN \\ THE INCLUSIVE SCHOOL
}

Jefferson Diego de JESUS ${ }^{1}$

Sueli FERNANDES ${ }^{2}$

RESUMO: Este trabalho tem como objetivo apresentar resultados de um estudo comparativo da política de educação bilíngue para surdos/as nos contextos da escola bilíngue e da escola inclusiva com atendimento educacional especializado (AEE) na Região Metropolitana de Curitiba. Para dar respostas à questão "como os sentidos da educação bilíngue, tal como expressos em documentos legais e nas reivindicações do movimento surdo, são incorporados às concepções dos professores nas escolas? valemonos da análise de dados coletados em pesquisa de mestrado em educação, à luz das reflexões trazidas por autores que se filiam ao campo dos Estudos Surdos em Educação. Os resultados do estudo comparativo apontam que são muitos ainda os desafios para garantir o direito à Libras como língua materna dos/as estudantes surdos/as nas escolas bilíngues e no AEE. A fragilidade no conhecimento da Libras e a ausência de critérios que considerem a fluência linguística para a atuação são aspectos comuns nos contextos investigados. Apesar do espaço concedido à Libras, ela é secundarizada em relação ao português que ainda figura como principal língua de interação e no currículo. A integração de objetivos da educação escolar e da educação linguística para surdos/as, desde a educação infantil, com investimento em políticas de formação continuada e reorganização do trabalho pedagógico, são princípios para que o direito à educação bilíngue esteja garantido, seja na escola inclusiva, seja na escola bilíngue para surdos/as.

PALAVRAS-CHAVE: Educação bilíngue para surdos/as. Escola bilíngue. Atendimento educacional especializado. Políticas educacionais.

RESUMEN: Esta investigación consiste presentar resultados de un estudio comparativo de la política de educación bilingüe para sordos en los contextos de la escuela bilingüe $y$ de la escuela inclusiva com atendimiento educacional especializado (AEE) en la Zona

\footnotetext{
${ }^{1}$ Universidade Federal do Paraná (UFPR), Paraná - Brasil. Professor do Setor de Ciências Humanas/UFPR. Vice Coordenador do Curso de Letras Libras/SCH/UFPR.

${ }^{2}$ Universidade Federal do Paraná (UFPR), Paraná - Brasil. Professora do Programa de Pós-Graduação em Educação - PPGE/UFPR. Linha Educação: Diversidade, Diferença e Desigualdade Social. Coordenadora do Curso de Letras Libras/Setor de Ciências Humanas/UFPR.
} 
Metropolitana de Curitiba. Para contestar a la cuestión “¿cómo los sentidos de la educación bilingüe, tales como los expresos en los documentos oficiales y en las demandas del movimiento sordo, son incorporados a las concepciones de los maestros en las escuelas? Para eso utilizamos análisis de datos recogidos en una investigación de maestría em educación, a la luz de las reflexiones propuestas por autores que se filian al campo de los Estudios Sordos em Educación. Los resultados del estudio comparativo apuntan que aún son muchos los desafios para garantizar el derecho a la Libras como lengua materna de los/as estudiantes sordos/as en las escuelas bilingües y en lo AEE. La fragilidad en el conocimiento de la Libras y la ausencia de criterios que consideren la fluência lingüistica para la actuación son aspectos comunes en los contextos investigados. Apesar del espacio concedido a la Libras, ella es puesta en según plan en relación al portugués que continua como principal lengua de interacción y en el currículo. La integración de los objetivos de la educación escolar y de la educación lingüistica para sordos, que comienza en la educación infantil, con investimento en políticas de formación continuada y reorganización del trabajo pedagógico, son principios para que el derecho a la educación bilíngües e garantice, sea en la escuela inclusiva, sea en la escuela bilingüe para sordos.

PALABRAS CLAVE: Educación bilingüe para sordos. Escuela bilingüe. Atendimiento educacional especializado. Politicas educacionales.

ABSTRACT: This paper aims to present the results of a comparative study of the bilingual education policy for the deaf in the contexts of the bilingual school and the inclusive school with specialized educational assistance (AEE) in the Metropolitan Region of Curitiba. To answer the question "how are the meanings of bilingual education, as expressed in legal documents and in the claims of the deaf movement, embodied in the conceptions of teachers in schools? We based our analysis on data collected in master's research in education, in the light of the reflections brought by authors from the field of Deaf Studies in Education. The results of the comparative study point out that there are still many challenges to guarantee the right to the mother tongue of deaf students in bilingual schools and AEE. The fragility in the knowledge of Libras and the absence of criteria that consider the linguistic fluency for the performance are common aspects in the investigated contexts. Despite the space granted to Libras, it is secondary in relation to Portuguese, which still shows up as the main language of interaction and in the curriculum. The integration of objectives of schooling and language education for the deaf, from early childhood education, with investment in policies for continuing education and reorganization of pedagogical work, are principles for the right to bilingual education to be guaranteed, whether in the inclusive school, or in bilingual schools for the deaf.

KEYWORDS: Bilingual education for the deaf. Bilingual school. Specialized educational assistance. Educational policies.

\section{Introdução}

Este trabalho tem como tema a educação bilíngue para surdos/as e contextualiza sua análise nas políticas educacionais nos anos 2000 em sua relação com a agenda política 
do movimento surdo. Nesse período, o campo da política educacional passa por uma transformação radical incorporando reivindicações dos movimentos sociais surdos ${ }^{3}$ mundiais em defesa da centralidade da língua de sinais no processo de escolarização e inclusão social, incorporando a educação bilíngue como principal estratégia de luta por uma educação inclusiva de qualidade. Essa mudança paradigmática passa a ser fundamentada em pesquisas orientadas pela vertente dos Estudos Surdos em Educação (SKLIAR, 1997, 1999; QUADROS e PERLIN, 2007) e respaldadas por documentos internacionais importantes na defesa de direitos humanos como é o caso da Convenção Internacional dos Direitos das Pessoas com Deficiência (BRASIL, 2007) que destaca a produção cultural e linguística das comunidades surdas como elementos para garantir o respeito à dignidade, a acessibilidade e a garantia da autonomia e liberdades individuais, combatendo a exclusão e o preconceito a esse grupo social.

De acordo com Quadros (1997, p. 27) “o bilinguismo é uma proposta de ensino usada por escolas que se propõem a tornar acessível à criança duas línguas no contexto escolar". No caso do Brasil, a proposta bilíngue toma como pressuposto a aquisição da língua brasileira de sinais (Libras) de forma espontânea e natural, como primeira língua (L1) dos/as surdos/as, no contato com outros usuários, de modo que a língua portuguesa escrita seria considerada a segunda língua (L2). Além disso, a condição "bicultural” na educação, como pontua Lopes (2007, p. 66), é um fator a ser considerado, pois os/as surdos/as "partilham de elos que os posicionam de formas específicas, ora como surdos/as - quando estão na comunidade surda -, ora como não ouvintes - quando estão entre ouvintes. ".

Por isso, quando se discute direito à educação dos/as surdos/as, o debate sobre as línguas envolvidas no processo educacional é essencial para se garantir igualdade nos padrões de aprendizagem e desenvolvimento das crianças surdas, em relação às demais crianças que não precisam da escola para ter acesso a sua língua materna (L1), na infância (FERNANDES, 2003). Assim, as bandeiras de luta do movimento surdo têm envidado seus esforços na defesa dos direitos humanos e linguísticos dos/as surdos/as, com prioridade à educação bilíngue no campo das políticas educacionais, com ações e programas que potencializem a cidadania bilíngue dos/as surdos/as brasileiros/as.

\footnotetext{
${ }^{3}$ Adotamos a definição de Brito (2013) de que o movimento social surdo brasileiro se configura como um sistema de relações sociais composto principalmente por pessoas surdas usuárias de Libras, grupos e organizações de surdos. A Federação Nacional de Educação e Integração Social dos Surdos (Feneis) representa institucionalmente o movimento, em nível nacional.
} 
Entretanto, embora o direito à educação bilíngue seja um consenso nacional na legislação, há uma divergência de entendimento que contrapõe a visão do movimento surdo àquela enunciada nos documentos da política nacional de educação inclusiva vigente. No âmbito das diretrizes da política de inclusão, a educação de surdos/as têm sido um campo de destaque, justamente pelas polêmicas acerca do lócus que melhor representaria a oferta da educação bilíngue para esse grupo de estudantes, já que, conforme Resende e Lacerda (2013, p. 402) "a construção dessa escola inclusiva para um grupo de pessoas que possui uma língua diferenciada e própria não parece ser uma tarefa simples".

A divergência na concepção e forma de organização da educação bilíngue foi alvo de inúmeros confrontos e mobilizações entre o MEC/SEESP e o movimento surdo, representado pela Federação Nacional de Educação e Integração dos Surdos (Feneis) por todo o Brasil, durante o processo de debate do projeto de lei do Plano Nacional de Educação - PNE e dos fóruns da Conferência Nacional de Educação (CONAE), entre 2010 e $2014^{4}$. Materializa-se nos textos legais a tensão da disputa da política educacional, a partir dos princípios ideológicos defendidos pelo Estado, representados pelo MEC, e a pauta do movimento surdo, atribuindo diferentes sentidos à educação bilíngue para surdos/as, conforme analisam Sturmel e Thoma:

Verificamos que os discursos produzidos no MEC procuram dar visibilidade à educação na escola comum como direito fundamental de todos, ou seja, a escola comum é vista como um espaço onde todos devem estar juntos e no qual as diferenças devem ser respeitadas e valorizadas. Os discursos que constituem os documentos do movimento surdo, por sua vez, marcam o direito linguístico como direito humano fundamental, entendendo que a escola comum não possibilita a garantia desse direito através da oferta do Atendimento Educacional Especializado em turno oposto ao da educação na classe comum com ouvintes. (STURMEL; THOMA, 2015, p.12) [grifos nossos]

Em síntese, a polêmica principal repousa na crítica do movimento surdo de que a escola inclusiva não garantiria o direito linguístico à Libras como direito humano fundamental dos/as surdos/as. A Política Nacional de Educação Especial na perspectiva da Educação Inclusiva (BRASIL, 2008) defende que a educação bilíngue para surdos/as deveria ser realizada em escola inclusiva, por meio do apoio de tradutores intérpretes,

\footnotetext{
${ }^{4}$ Para relato completo ver Revista da Feneis (2013), e Campello; Rezende (2014).
} 
Educação bilíngue para surdos/as: um estudo comparativo da escola bilíngue e do atendimento educacional especializado (AEE) na escola inclusiva

com Atendimento Educacional Especializado (AEE) complementar, no contraturno da escolarização.

A Feneis critica essa perspectiva e argumenta que a educação bilíngue não é compatível com o AEE pelo fato de que na escola inclusiva o português é a língua oficial na comunicação e no ensino. Quando a Libras está presente, ela é utilizada por uma ou duas pessoas sinalizadoras, de forma precária, negando-se interações significativas em línguas de sinais, como língua de instrução, interação e socialização, com sinalizadores fluentes. Como alternativa, propõe que o direito à Libras como língua materna seria garantido se fossem organizadas classes bilíngues em escolas comuns ou escolas bilíngues para surdos/as (BRASIL, 2014).

Nesse cenário tenso de disputas, a principal reivindicação do movimento surdo foi contemplada na Estratégia 4.7- Meta 4 do PNE (BRASIL, 2014) e reafirmada na Lei Brasileira de Inclusão da Pessoa com Deficiência n $13.146 / 2015$, que institui o Estatuto da Pessoa com Deficiência:

Garantir a oferta de Educação bilíngue, em Língua Brasileira de Sinais (libras) como primeira língua e na modalidade escrita da língua portuguesa como segunda língua, aos alunos surdos e deficientes auditivos de 0 a 17 anos, em escolas e classes bilíngues inclusivas, nos termos do art. 22 do Decreto $\mathrm{n}^{\circ} 5.626$, de 22 de dezembro de 2005, e dos arts. 24 e 30 da Convenção (BRASIL, 2014)

IV - oferta de educação bilíngue, em Libras como primeira língua e na modalidade escrita da língua portuguesa como segunda língua, em escolas e classes bilíngues e em escolas inclusivas; (BRASIL, 2015) [grifos nossos]

Contudo a classe/escola bilíngue ser considerada como uma possibilidade respaldada na política pública, na maciça realidade dos municípios brasileiros, a oferta educacional dominante para estudantes surdos/as se realiza por meio do AEE em escola inclusiva.

Contextualizado o cenário político que delimitou esta investigação, o objetivo geral deste trabalho é apresentar resultados de um estudo comparativo da política de educação bilíngue para surdos/as nos contextos da escola bilíngue e da escola inclusiva com atendimento educacional especializado (AEE) na Região Metropolitana de Curitiba. Nossa intenção é aprofundar subsídios ao debate da política educacional para surdos/as, a partir de reflexões sobre a experiência concreta de uma realidade local. 


\section{Educação bilíngue em foco: a pesquisa}

Para dar respostas à indagação de "como os sentidos da educação bilíngue, tal como expressos em documentos legais e nas reivindicações do movimento surdo, são incorporados às concepções dos professores nas escolas?" valemo-nos da análise de dados coletados em pesquisa de mestrado $^{5}$ realizada no Programa de Pós-Graduação em Educação/Linha de Educação: Diversidade Diferença e Desigualdade Social, da Universidade Federal do Paraná, em 2016. A busca de subsídios para análise nos dois contextos de ensino (escola bilíngue/escola inclusiva) foi motivada pela compreensão de que a política de educação bilíngue se materializa a partir das concepções e práticas do trabalho desenvolvido nas escolas.

Desse modo, para a coleta de dados, selecionamos uma escola bilíngue para surdos/as, localizada em Curitiba (aqui denominada EB), e duas escolas inclusivas com atendimento educacional especializado, localizadas em Araucária e Pinhais (aqui denominadas AEE 1 e AEE2), conforme mapa na Figura 1.

Figura 1: Municípios de localização das escolas

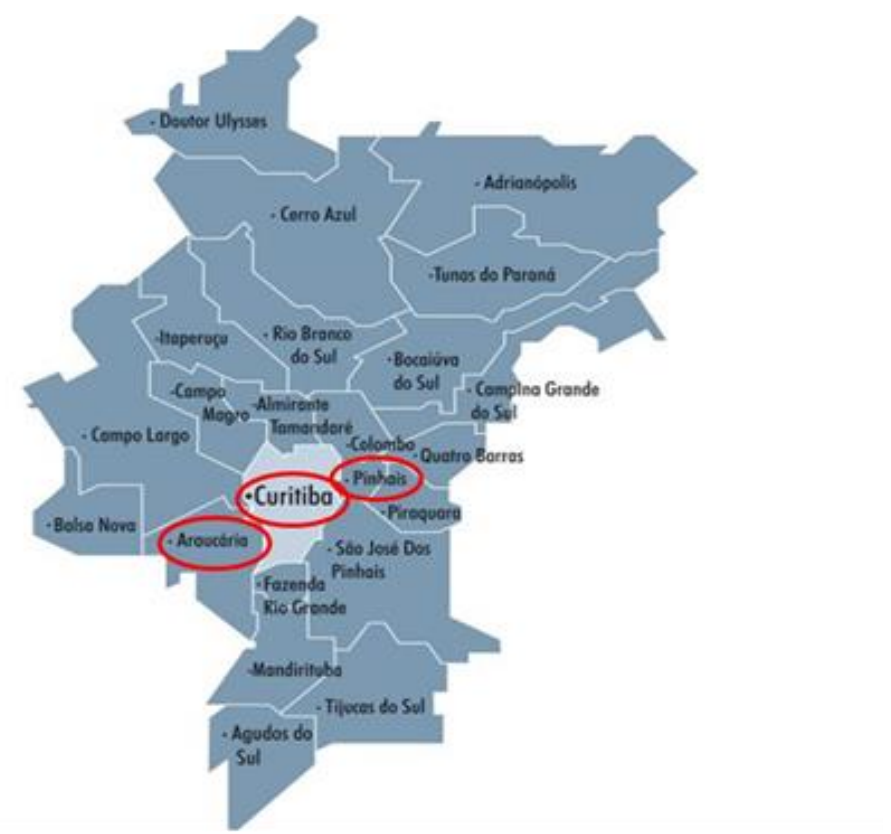

Fontes: 〈http://www.policiacivil.pr.gov.br/modules/conteudo/conteudo.php?conteudo=71>.

A escola inclusiva AEE-1, localizada no município de Pinhais, região metropolitana norte, oferece atendimento educacional especializado para 29 estudantes

\footnotetext{
${ }^{5}$ Jesus (2016)
} 
surdos/as matriculados na educação infantil (2), ensino fundamental (24) e ensino médio (3). A escola inclusiva AEE-2, localizada no município de Araucária, região metropolitana sul, realiza atendimento a 24 estudantes surdos/as matriculados na educação infantil (3), ensino fundamental (16), ensino médio (2) e ensino superior (3). A escola bilíngue, em Curitiba, é a mais antiga instituição especializada na área, fundada em 1953, e principal estabelecimento da rede estadual de ensino a ofertar educação básica exclusivamente para surdos/as, no Paraná. São 96 estudantes surdos/as matriculados na educação infantil (3), ensino fundamental (51), ensino médio (30) e ensino técnico (12). No total dos três estabelecimentos estão matriculados 141 estudantes surdo/as com concentração no ensino fundamental. Chama a atenção, o inexpressivo número de crianças surdas na educação infantil (8) nos três municípios, etapa mais importante para o acesso à Libras na infância, como discutido anteriormente.

Importante destacar que na análise dos projetos político-pedagógicos dos estabelecimentos de ensino identificamos que a proposta de educação bilíngue está indicada como objetivo da educação de surdos/as na EB e AEE1, sendo mencionada, não explicitamente, no AEE-2. Em diferentes perspectivas, Libras e português são línguas que circulam nos três contextos de ensino pelos relatos coletados.

Quanto aos participantes da pesquisa, trata-se de 11 professoras, todas do sexo feminino, diretamente envolvidas no atendimento educacional de surdos/as, indicadas pelas diretoras das escolas. Foram entrevistadas 3 professoras em cada um dos municípios com AEE (uma professora surda, em cada escola) e cinco professoras na escola bilíngue (3 ouvintes e 2 surdas). As entrevistas foram realizadas no ambiente das escolas pelo pesquisador surdo ${ }^{6}$ com a mediação do tradutor intérprete de Libras, registradas em vídeo e posteriormente traduzidas e transcritas para o português. A identidade das entrevistadas será preservada nos fragmentos que ilustrarão a análise, por meio da denominação $\mathrm{P}$ (professora) seguida de seu contexto de atuação e numeração (P-AEE 1, 2, 3, 4, 5, 6 ou P-EB 7, 8, 9, 10 e 11). No caso de professora surda, utilizaremos PS na indicação.

A entrevista semiestruturada contemplou questões relacionadas aos seguintes eixos temáticos: (i) dados pessoais e formação (sexo, faixa etária, escolaridade, tempo de serviço (na área), carga horária de trabalho, onde/como aprendeu Libras, formação na

\footnotetext{
${ }^{6}$ Jesus (2016), pesquisador surdo, realizou as entrevistas em Libras para avaliar, em interação espontânea, o nível de conhecimento da Libras pelas professoras, variável que poderia ser considerada na análise. No entanto, com exceção das três professoras surdas, as demais, ouvintes, optaram pela entrevista com apoio do tradutor intérprete, em português.
} 
área de Libras); (ii) concepção de educação bilíngue; (iii) gestão do sistema de ensino e (iv) organização do trabalho pedagógico.

Neste trabalho, apresentaremos como foco a discussão envolvida no direito à Libras no contexto escolar, a partir dos eixos citados, contemplando a interação e ensino em Libras como primeira língua (L1). A partir dos relatos das professoras sobre as práticas desenvolvidas na escola, buscamos identificar diferenças/semelhanças nos dois contextos de ensino investigados.

\section{Sobre a concepção de educação bilíngue}

Independente do contexto em que atuam, as professoras reproduzem, em linhas gerais, os discursos oficiais sobre a educação bilíngue para surdos/as, resumindo sua definição à questão das línguas na educação, ou seja, o ensino de Libras e português. Quando provocadas a estabelecer uma hierarquia nas relações entre ambas as línguas, pudemos identificar diferenças qualitativas nas respostas, atribuindo ora à Libras, ora ao português posição de destaque.

Todas as professoras da escola bilíngue responderam que a Libras é a língua mais importante na educação dos/as surdos/as, destacando seu caráter de língua natural:

"Lingua de Sinais, Libras. Porque a Libras é a L1 dos surdos, conforme no bilinguismo, a L1 do surdo é a Língua de Sinais". (PS-EB 8)

"Eu acredito que seja Libras, porque é a língua natural deles. Eu acho que mais do que você passar o conhecimento, o processo de educação depende de você conhecer, do aluno poder se comunicar onde ele estiver, de poder raciocinar na sua língua, raciocinar na língua que é natural para ele. Então, acredito que para a educação de surdos a Libras é essencial, mas em todos os momentos, não só ali na hora em que o professor está passando um conhecimento, falando, tem que haver uma troca, tem que ser com a tia da cozinha, tem que ser com a direção, tem que ser com a pedagoga, todos deveria estar falando Libras para que ele tenha acesso as mais diversas pessoas dentro do centro de ensino". (PS-EB 9)

"Primeiro lugar a Língua de Sinais, porque é a língua própria do surdo, que é o jeito que ele vai se identificar mais". (P-EB 11)

Professoras do AEE também apontam que a Libras é importante, mas fazem ressalvas ao português como indispensável no desenvolvimento dos/das surdos/as, seja 
porque a sociedade é ouvinte, seja porque a Libras está restrita ao espaço da escola, dando a ela destaque como língua principal no processo escolar:

"Não faz sentido não ter domínio do Português e saber perfeitamente Libras, no bilinguismo o que falta é mais fluência na Língua Portuguesa" O Português e a Língua de Sinais devem ser ensinados no mesmo nível. Não adianta saber Libras perfeitamente e ser fraco em Lingua Portuguesa. O aluno deve sim saber muito bem o Português e Libras, pois no futuro esse aluno precisa de comunicação fora dos espaços sinalizantes". (PS-AEE-1).

"A Libras, porque o pensamento deles é fundamentalmente visual. Acho que primordial é isso, mas não pode esquecer da Língua Portuguesa porque eles estão inseridos num contexto onde todos, a maioria é ouvinte." (P-AEE 2)

"A minha opinião é a seguinte: mais importante, e melhor, é a Língua de Sinais, claro. Mas também é importante ele saber português, porque em todos os lugares a língua que predomina é o Português, o surdo precisa conhecer o Português na modalidade escrita. Mas o ensino e as interações são feitos em Lingua de Sinais, claro, a primeira língua". (P-AEE 3)

"Língua de Sinais tem um tempo, o ensino do Português tem tempo mais curto, porque as explicações são todas em Lingua de Sinais. Eu acho que deveria ter um tempo maior dedicado ao ensino do Português, de palavras fazendo a ligação com os sinais. A Lingua de Sinais eles já sabem, mas falta mais tempo para o Português. (P-AEE4)

\footnotetext{
"Bom eu acredito que a Língua de Sinais seria de grande importância se a gente tivesse uma comunidade surda bem atuante. Mas a gente não tem isso, a gente tem a Língua de sinais só dentro da escola e dentro do AEE, seria, o necessário seria essa comunicação efetiva em todos os espaços, mas não é o que nós temos hoje. Então a gente tem que lidar com o que nós temos. Nós temos oralidade e a Língua de Sinais aí a gente tem que fazer esse paralelo, lógico que a gente dá um valor imenso na Língua de Sinais, mas são as duas línguas que acompanham ele no processo educativo" (P-AEE 5)
}

Chamou-nos atenção não apenas a suposta superioridade e legitimação do português como principal língua no currículo, mas a manutenção da lógica tradicional que a língua falada deva ter lugar no atendimento especializado pelo argumento da necessidade de "comunicação":

"E aí, às vezes, eu percebo que eu me comunico em Libras e a criança fica me olhando e não me entende, aí eu pergunto, os sinais básicos eles já conhecem: entendeu? Sabe? Como? Enfim..., mas não entendem, aí eu falando aí em algumas situações eu utilizo pra reforçar esse processo. Não sei se está certo ou errado, eu acredito que não, porém, eu vejo que as vezes é essencial. [...] a gente sempre está 
se policiando para não falar[...] Mas, como eu falei, tem vezes que as crianças não entendem, aí a gente acaba falando em algumas situações, mas é sempre visando o surdo, enfim, depende muito $(P$ AEE2)

Não ouvir e não falar foram os aspectos que determinaram a "anormalidade" surda e um modelo educacional para tratar, recuperar e, quem sabe, curar o déficit biológico dos/das surdos/as. Para Carlos Skliar, importante pesquisador da diferença surda, essa concepção se enquadra na visão clínico-terapêutica que tem como princípio a noção de que o desenvolvimento cognitivo está condicionado ao maior ou menor conhecimento da língua oral (SKLIAR, 1997, p.110). Para Da Cunha Pereira (2014) a abordagem oralista ainda presente na educação de surdos/as atualmente, hoje sendo justificada pelos alunos implantados, como podemos verificar nesse depoimento:

\begin{abstract}
"Depende novamente do caso, como a X acabou de falar. Na questão dos implantados é um outro desenvolvimento, focado na língua oral ali, enfim no oralismo mesmo, estimulando como ouvinte, desenvolvimento normal. E no caso do surdo, eu priorizaria, vejo que é dessa maneira, a questão da Libras paralelo com a Língua Portuguesa também escrita, a importância disso".(PS-AEE 4)

"Então seria realmente a Libras para o surdo. Só que a gente aqui no AEE nós temos os implantados também, que utilizam a língua falada mesmo, a oralidade. Então o que seria para o surdo que a gente utiliza aqui no AEE, seria a Língua de Sinais e também temos os implantados e seria o Português". (P-AEE 6)
\end{abstract}

Muito interessante perceber que a questão das relações de poder entre a língua de sinais e a língua portuguesa na educação de surdos/as é mais evidenciada no contexto da escola inclusiva, já que a língua oral/escrita é predominante. Fernandes e Moreira (2009) argumentam que Libras e língua portuguesa estão em tensão constante nas interações verbais no território escolar, posto que são línguas marcadas por relações de poder explicitamente assimétricas na sociedade. As autoras explicam que desse desequilíbrio de forças resultam programas de bilinguismo assimilacionistas, o que significa dizer que mesmo que a língua minoritária (no caso a Libras) seja utilizada na escola no início do processo e seu valor seja reconhecido em alguns espaços, ela passa a ser substituída pelo português, conforme o aluno vai avançando na escolarização. É como se a Libras fosse utilizada como ponte, para a aprendizagem da língua mais importante:

[...] esse tipo de bilinguismo, "assimilacionista" ou "fraco", que vem sendo construído, promove a subalternização de uma língua em relação a outra com vistas a seu desaparecimento e desencoraja os estudantes surdos de utilizarem aquela que seria sua língua natural - a Libras. Pela 
imagem negativa gerada socialmente acerca de si, os surdos sentem-se menos capazes de se identificar com a cultura nacional, caso não aprendam a língua principal da sociedade, em nosso caso o português (FERNANDES; MOREIRA, 2009, p. 232)

\section{Profissionais bilíngues na educação de surdos/as}

A síntese que podemos obter da leitura geral dos fragmentos até aqui selecionados demonstra que a Libras está presente em todos os contextos de ensino, com maior ou menor relevância na prática pedagógica. Queremos destacar o principal fundamento da educação bilíngue para surdos/as que é aprender a Libras na infância, a fim de que seu processo de aquisição respeite as mesmas etapas de desenvolvimentos da linguagem previstas para qualquer criança. Nesse sentido, a importância da escola para a aprendizagem da Libras como língua materna, ou primeira língua (L1), apropriada na interação com professores bilíngues, já que a maioria das crianças nasce em lares ouvintes, não foi mencionado nos relatos. A reflexão de valorizar o ambiente linguístico da escola, na ausência de interlocução em língua de sinais na família, não foi lembrada por nenhuma professora.

Para Resende e Lacerda (2013, p. 412), a relevância de que os processos educacionais bilíngues tenham início na educação infantil é um fato incorporado na legislação, mas sabe-se que ainda são poucas as experiências educacionais bilíngues nesta etapa de ensino, implicando ingresso de alunos no ensino fundamental com pouco desenvolvimento de linguagem e, portanto, com poucas possibilidades de significação dos conhecimentos em circulação no interior da escola.

Pesquisadores/as e intelectuais surdos/as (BRASIL, 2014) advogam que a escola precisa prever espaços para interação, conversação, contação de histórias em Libras, uma vez que a maioria das crianças surdas não tem acesso a essa língua no ambiente familiar. As atividades da educação infantil têm como objetivo também a aquisição da linguagem e, por isso, os profissionais que atuam nessa etapa sevem ser, prioritariamente, surdos/as e professores ouvintes fluentes em Libras, como referência de língua e da comunidade surda. Essa questão da relação entre as línguas e da prioridade dada a língua de sinais no processo educacional, dependeria da presença de profissionais bilíngues na educação.

Davies (apud QUADROS, 1997) descreve três categorias de profissionais bilíngues: os/as professores/as de Libras (preferencialmente surdos/as), os/as professores/as bilíngues (surdos/as e /ou ouvintes), responsáveis pelo ensino dos 
conteúdos escolares e do português como L2, que devem ser fluentes em Libras/língua portuguesa e os tradutores e intérpretes de Libras, responsáveis pela tradução (da Libras para o português oral, da Libras para escrita, do português oral para a Libras), na ausência de professoras bilíngues. Na mesma lógica, o Decreto Federal 5626/2005 aponta três profissionais em ação no processo de educação bilíngue: o professor de Libras (preferencialmente surdo), o professor bilíngue e o tradutor intérprete de Libras. Sobre os dois últimos é importante esclarecer o trabalho de cada um, pois, enquanto o tradutor intérprete de Libras traduz e interpreta a língua de sinais para a língua falada e vice-versa em quaisquer modalidades que se apresentar, o professor bilíngue tem o papel fundamental associado ao ensino e, portanto, completamente inserido no processo interativo social, cultural e linguístico (QUADROS, 2007).

A fala das professoras opera um reducionismo nos papeis do/a professor/a surdo/a (ensinar Libras) e do professor ouvinte (ensinar português); extraímos de seus relatos essa percepção de que a cada um cabe uma "língua”, sem reflexões mais amplas sobre o processo de educação integral:

\footnotetext{
"O papel do profissional ouvinte é trabalhar a Língua Portuguesa na modalidade escrita, eu vejo. Então assim, a produção da criança surda as vezes vem com faltas de coesão, artigo, clareza em algumas situações, ai vem o profissional ouvinte para fazer essa correção" ( $P$ AEE2).
}

O professor regente usa a Língua de Sinais para todo o ensino e traz para ele a segunda língua que é a Língua Portuguesa, Lingua Portuguesa escrita, sempre a Língua Portuguesa escrita (AEE8)

"Numa escola bilíngue ideal, professores surdos, professores ouvintes que dominem fluentemente a Libras, intérpretes, principalmente em relação, para ter contato com a família, e enfim... talvez pessoas da comunidade surda, instituições, federações que participem também." (PS-EB 9)

"Por exemplo a minha disciplina é Libras, às vezes os alunos me perguntam sobre determinado vocabulário, e eu sou bilíngue, respondo! Mas a minha função não é ensinar Língua Portuguesa, é ensinar Libras! Eu posso passar vocabulários se eles me perguntam, é um pouco complicado, mas eu acho possivel”. (PS-EB 8)

O professor surdo tem sido apontado por muitos estudiosos (CAMPELLO, 2007;

REIS, 2006; MARTINS, 2010) como profissional bilíngue de grande importância na educação de surdos/as, pelas possibilidades de identificação como modelos linguísticos e 
Educação bilíngue para surdos/as: um estudo comparativo da escola bilíngue e do atendimento educacional especializado (AEE) na escola inclusiva

culturais para as crianças surdas. Padd Lady (2003) declara que o/a professor/a surdo/a é o modelo ideal e necessário para que a criança surda possa construir sua identidade positiva, pois, além do referencial linguístico, faz circular artefatos da cultura surda, da arte surda, da literatura surda, enfim, do jeito de 'ser surdo' no mundo e a importância dessa experiência estar incorporada ao currículo. Para Skliar, a educação bilíngue para surdos/as, partindo de uma perspectiva política, deve ser construída a partir dessa apreensão socioantropológica que os percebe como sujeitos culturais e reconhece a língua de sinais como símbolo identitário, de maneira que "permite reinterpretar suas tradições comunitárias como construções históricas, culturais, linguísticas e não simplesmente como um efeito de supostos mecanismos de compensação biológicos e/ou cognitivos" (SKLIAR, 1999, p. 24). Esse discurso é enunciado na voz de algumas professoras entrevistadas:

\begin{abstract}
"O professor surdo tem uma identidade própria que o ouvinte infelizmente não tem para estar ensinando, para estar trabalhando com a criança. [..] E o professor surdo ele é a referência".(AEE2)

Então, o professor surdo, fora o seu conteúdo, ele tem uma experiência acumulada de vida que ele pode servir de exemplo. [...] o professor surdo é importantíssimo porque ele é o exemplo daquilo que ele já superou $(P S-E B 9)$.
\end{abstract}

Observamos que todos os profissionais indicados nas diretrizes legais estão presentes nos dois espaços, muito embora o tradutor intérprete de Libras fosse, por princípio, um profissional que atuaria apenas no contexto da escola regular. Na escola bilíngue investigada, justificou-se a presença de intérprete nos anos finais do ensino fundamental e médio, em razão de não haver professores das diferentes disciplinas com conhecimento da Libras. A figura do intérprete de Libras tem sido bastante destacada no processo de educação inclusiva como o principal apoio para acessibilidade linguística dos estudantes surdos/as em escolas regulares. Quadros (2007) analisa que em muitos contextos de escolarização os intérpretes acabam assumindo a função de professoras, pois são os únicos profissionais na escola a dominar a língua de sinais como língua de instrução. Isso aparece no depoimento do AEE:

\footnotetext{
"Ahé importante falar que assim, o intérprete também varia, no sentido assim: tem aquela criança que já conhece Língua de Sinais, então ela tem um intérprete, não sei se é essa palavra que eu posso usar: um intérprete técnico, mas que acaba também se tornando um apoio pedagógico no momento. E tem aquela criança que está aprendendo ainda, que está começando, aí ele tem esse intérprete que assume mais
} 
a função de apoio pedagógico com ele, tem um caso assim, que ainda está começando com os sinais, que ainda utiliza da fala em algumas situações, é um processo diferente" (P-AEE2).

O depoimento demonstra certa ambiguidade em relação à função desempenhada pelo intérprete em escola inclusiva. Sabe-se que apenas estudantes com idade mais avançada (adolescentes), nos anos finais do ensino fundamental e ensino médio, poderiam se beneficiar da mediação do tradutor intérprete de Libras em sua função objetiva de tradução linguística. Antes disso, as crianças surdas ainda em processo de aprendizado da Libras, não tem fluência e maturidade para perceber a diferença na função atribuída à professor e intérprete, que acaba realizando o "apoio pedagógico", como demonstra o relato.

\section{A fluência linguística dos profissionais}

O domínio da língua de sinais seria um princípio fundamental para atuar na educação de surdos/as, pois seria uma obviedade questionar se a fluência em inglês, ou alemão, seria condição para trabalhar em uma escola internacional bilíngue que previsse essas línguas no currículo.

Embora óbvia, essa discussão é muito complexa quando se trata de contextos bilíngues em que uma das línguas tem menos prestígio social que a outra, como é o caso da Libras e da língua portuguesa. Há uma tendência em não se levar em conta essa desigualdade no status social quando se debate a política educacional para surdos/as.

Kristina Svartholm, pesquisadora sueca, pioneira em programa de bilinguismo para surdos/as afirma que em uma escola ou programa bilíngue, o professor deve ter conhecimentos das estruturas e características típicas das duas línguas, com formação pedagógica e metodológica baseado na linguística para tornar central o ensino de da língua materna/primeira língua, em usos "tais como argumentação, discussão de assuntos abstratos, para criar e testar hipóteses, para generalização, para tirar conclusões entre outras" (SVARTHOLM, 2014, p. 41).

Nesse sentido, professoras surdas destacam a necessidade de as professoras ouvintes serem bilíngues para que a comunicação seja direta, já que os/as surdos/as são minoria na escola e o ensino seja efetivo, sem a dependência do intérprete; só reconhecem a necessidade do apoio do intérprete, porque as professoras não dominam Libras. 
"Precisa de professor ouvinte que domine Libras, na educação bilíngue o ensino precisa ser em Libras, não precisa ter um intérprete porque o professor sabe muito bem Língua de Sinais. Se o professor não sabe Libras, e precisa do intérprete, a informação sempre vai passar do professor para o intérprete e depois para a turma, isso se torna dependência do intérprete". (PS-AEE 4)

"Precisa de profissionais experientes na área da surdez, que conheçam a cultura surda, que entendam o que o surdo sente, quais as dificuldades, os motivos pelos quais os surdos sentem de tal forma, também conhecer o contexto familiar. Não basta apenas saber Libras, tem que ter conhecimento sobre o sujeito surdo. Tem que saber o que é o bilinguismo, e qual o papel do profissional bilíngue. Esse profissional precisa ser fluente em Libras, para que a comunicação aconteça de forma natural sem nenhum bloqueio, então a fluência tem que vir da parte desse profissional e também do surdo".(PS-EB 8)

Por isso, um importante variável para avaliar a efetividade da política de educação bilíngue diz respeito à proficiência linguística dos profissionais envolvidos diretamente na educação dos estudantes surdos/as. Se a fluência linguística em Libras seria uma condição para atuar na educação de surdos/as, quais seriam os critérios para a seleção de professores/as?

A resposta a essa questão revelou ausência e precariedade na política de seleção das secretarias de educação. Parte das professoras não soube responder sobre critérios de seleção, embora a metade delas trabalhem com pessoas surdas há mais de 10 anos. Com exceção das professoras de Libras, de quem se exigiu habilitação para o ensino da língua de sinais, não houve critérios de formação ou fluência em Libras para a atuação. No AEE municipal o ingresso se dá por meio de concurso público e como a educação especial não exige, não há critério de formação linguística para atuar na área. As professoras da EB, na rede estadual, também relatam que a falta de conhecimento linguístico também não impede a atuação:

\footnotetext{
"Mas não tem, por exemplo: professor em sala regular, na inclusão,pode acontecer de conhecer Libras por uma questão própria, mas não tem essa exigência" (P-AEE2)

"No dia da distribuição de aula tinha o colégio EB e eu escolhi, eu não sabia que era uma escola para surdos, lá o responsável pelo núcleo não tem nenhuma informação, eu perguntei que escola era essa, ele me disse que ficava na Vila Izabel, e eu peguei por ser próxima a minha escola e eu não sabia que era escola para surdos"( $P$-EB7)
}

"Então, eu tinha interesse em trabalhar com surdos, em escola bilíngue, mas era mais por curiosidade, eu não tinha essa formação. 
[...].Então eu caí aqui meio que de para quedas porque a minha formação nunca foi voltada para trabalhar com surdos" (P-EB10)

"Pelo visto não tem muitos critérios, porque a própria questão do intérprete não tem concurso, é só por contrato temporário. $O$ professor para trabalhar na escola bilíngue não foi pedido, em nenhum momento, nenhum tipo de proficiência para mim. Então, eu não sei como era antes, mas esse ano, que foi o ano que eu entrei aqui, não havia critério nenhum, quem quisesse basta boa vontade" (PS-EB9)

Na verdade, o critério para atuação está apontado no Decreto Federal 5626/2005 (art. 14, parágrafo $1^{\circ}$, inciso III) quando dispõe "sobre a necessidade de o professor regente de classe ter conhecimento acerca da singularidade linguística manifestada pelos alunos surdos", o que inclui o uso da língua de sinais na comunicação entre professores/as e alunos/as surdos/as. Apesar de a legislação existir, e apontar a questão do conhecimento da Libras como elemento fundamental na atuação, ela não vem sendo respeitada, como demonstram os relatos. A professora surda da EB é a única que se posiciona criticamente em relação a essa situação:

\begin{abstract}
"Não, eu não concordo de jeito nenhum. Eu acho que assim, deveria talvez, ter na SEED assim temos um colégio para surdos, bilíngue, o professor que tiver interesse tem que ter proficiência [...] e talvez se a secretária de educação também oferecesse cursos dentro da área, dando curso de Libras para os professores, talvez muita gente tivesse interesse. Então quem estava aqui eu não sei quem era, nem como chegou, não sei como foi o critério anteriormente [...] mas para o aluno é interessante que o professor já tenha a sua formação concluída, que esteja apto na língua dele, na língua L1, que possa desenvolver seu trabalho com excelência, não correr atrás enquanto ele está querendo se formar. Então realmente não existem critérios, não tem como concordar com isso. (PS-EB9)
\end{abstract}

Se os docentes não têm formação linguística e as crianças surdas estão em fase de aquisição da língua e também são pouco fluentes como se forma o ambiente bilíngue debatido como fundamental no processo de bilinguismo na educação? Em pesquisa de doutorado Fernandes (2003) comenta que os professores ouvintes utilizavam o espaço da escola para aprender a língua de sinais, pois era o único local em que tinham contato com surdo. O paradoxo dessa situação é alarmante: se a escola é o espaço para o professor aprender a língua pelo meio da qual vai ensinar, como os/as surdos/as aprendem os conteúdos escolares?

Trocando em miúdos: para que o aluno surdo tenha acesso à língua de sinais e às mesmas oportunidades educacionais e sociais que os demais alunos, ele necessita de professores bilíngues, já que os educadores 
surdos representam um grupo minoritário nas escolas; como a maioria dos professores é ouvinte, há uma inversão de papéis e a escola se transforma no espaço privilegiado para a aprendizagem da língua de sinais na interação com seus alunos surdos. Quem ensina quem? O que se ensina nas escolas? Que língua de sinais é essa que os alunos surdos vêm aprendendo com seus professores ouvintes? (FERNANDES, 2003, p. 145)

Os depoimentos demonstram que, na verdade, definir a educação como "bilíngue", sendo que as professoras não compartilham plenamente a mesma língua do aluno seria uma contradição na política educacional, já que "para realizar o bilinguismo dentro das escolas é preciso assumir a participação de duas línguas, garantindo o conhecimento de cada uma e refletindo sobre o lugar de cada uma no processo de aprendizagem" (VIEIRA, 2011,)

\section{Considerações finais}

São estas duas línguas - Libras e português - que definem a educação bilíngue para surdos/as no campo das políticas educacionais, na organização do sistema de ensino, na formação de professoras e na política curricular.

A pesquisa trouxe importantes contribuições acerca dos desafios voltados às políticas de educação bilíngue para surdos/as, já que analisou o discurso em prática nos dois contextos de ensino contemplados como alvo de disputas no cenário político: escola bilíngue e escola inclusiva. O paradoxo inclusão/exclusão tem fronteiras imprecisas quando tratamos da educação de grupos vulneráveis fora dos padrões homogeneizadores, exatamente como acontece com pessoas surdas que são "incluídas" nas escolas, mas ao falarem uma língua diferente dos demais alunos, acabam excluídos do acesso ao conhecimento, por meio de sua língua minoritária.

Como pudemos observar neste trabalho, para o direito à educação bilíngue estar progressivamente se consolidando como um fundamento da política educacional, a maior dificuldade tem sido reconhecer que as necessidades diferenciadas dos/as surdos/as exigem mudanças no ambiente linguístico das escolas, que foram historicamente pensadas para estudantes ouvintes como espaços de circulação apenas da língua portuguesa.

Sobre as concepções de educação bilíngue, independente do contexto em que atuam, as professoras tão somente reproduzem o discurso legal oficial e politicamente correto, citando a presença das duas línguas na escola. No entanto, ao aprofundarmos a 
análise dos fundamentos educação bilíngue que permitiriam garantir que a Libras seja ensinada e aprendida como primeira e principal língua no processo educacional, desde a educação infantil, percebemos inúmeras contradições entre teoria e prática.

Os resultados do estudo comparativo apontam que são muitos ainda os desafios para garantir o direito à Libras como língua materna dos/as estudantes surdos/as nas escolas bilíngues e no AEE. A fragilidade no conhecimento da Libras e a ausência de critérios que considerem a fluência linguística para a atuação são aspectos comuns nos contextos investigados. Apesar do espaço concedido à Libras, ela é secundarizada em relação ao português que ainda figura como principal língua de interação e ensino, em sala de aula.

Nossa análise demonstra que seja na escola bilíngue, seja no AEE em escolas inclusivas, os problemas para a implementação da educação bilíngue são idênticos e passam pela ausência de políticas de formação e critérios de seleção de corpo docente bilíngue para atuar na mediação do processo educacional. Professoras surdas e ouvintes observam a importância de que a fluência em língua de sinais seja o principal conhecimento para atuar na área, mas denunciam a falta de medidas efetivas para estabelecer critérios na contratação de professores, cujo foco seja a política linguística da escola, por parte do poder público.

A maioria das escolas constitui um ambiente monolíngue em português, pois seus estudantes e professores são ouvintes que falam/compreendem/leem/escrevem a língua nacional. Apesar disso, a escola inclusiva com AEE tem se colocado como a forma hegemônica na educação de surdos/as, na absoluta maioria dos municípios brasileiros.

Nesse sentido, faria sentido a defesa de escolas e classes bilíngues, não como se apresentam na atualidade, mas pensadas como estratégia política de médio e longo prazo, para buscar a integração entre objetivos da política inclusiva e da política linguística bilíngue. Formação de corpo docente bilíngue, materiais didáticos em Libras, história e cultura das comunidades surdas no currículo e maior visibilidade social da Libras para além dos muros escolares, seriam medidas essenciais para assegurar o direito à Libras como língua materna, desde a educação infantil.

Para que a política de educação inclusiva seja consistente há que se articular objetivos da educação escolar e de educação linguística para surdos/as, desde a infância, pois: 
bilíngue - e a prática cotidiana das escolas - a educação especial. $\mathrm{Na}$ atual configuração da educação inclusiva e do atendimento educacional especializado (AEE) a Libras não assume centralidade como língua principal na dialogia que envolve estudantes surdos nas escolas. Crianças surdas demandam essas experiências para se tornarem membros efetivos das comunidades linguísticas que lhes dariam o direito à Libras como língua materna. A inexistência de espaços comunitários para sua circulação e complexificação nega à Libras seu caráter ontológico de língua com potencial para se tornar patrimônio cultural da sociedade brasileira (FERNANDES e MOREIRA, 2014, p.66).

Desdobramentos futuros, apontam para formulações que levem à materialização da escola/classe bilíngue inclusiva, nos próximos dez anos, como anuncia o PNE (BRASIL, 2014), para efetivar o direito das crianças surdas a aprender a Libras como língua materna nas escolas de cada um dos municípios brasileiros.

\section{REFERÊNCIAS}

BRITO, Fábio Bezerra de. O movimento social surdo e a campanha pela oficialização da língua brasileira de sinais. Tese (Doutorado em Educação). Faculdade de Educação da Universidade de São Paulo. São Paulo: s.n., 2013. P.275

BRASIL. Lei n. 13.146, de 6 de julho de 2015. Institui a Lei Brasileira de Inclusão da Pessoa com Deficiência (Estatuto da Pessoa com Deficiência). Disponível em: <http://www.planalto.gov.br/CCIVIL_03/_Ato2015-2018/2015/Lei/L13146.htm>. Acesso em: 10 de abr. de 2016.

\section{BRASIL. Política Nacional de Educação Especial na perspectiva da Educação} Inclusiva. Disponível em: $<$ http://portal.mec.gov.br/seesp/arquivos/pdf/politica.pdf $>$. Acesso em: 15 fev. 2016.

BRASIL. Convenção Internacional dos Direitos da Pessoa com Deficiência. Nova York, 2007. Disponível em: <http://www.inr.pt/content/1/1187/convencaosobre-osdireitos-das-pessoas-com-deficiencia> . Acesso em: 17 maio 2016.

BRASIL. Decreto $n^{0}$ 5.626, de 22 de dezembro de 2005. Regulamenta a Lei $n^{\circ} 10.436$, de 24 de abril de 2002, que dispõe sobre a Língua Brasileira de Sinais - Libras e o art. 18 da Lei n 10.098 , de 19 de dezembro de 2000. Diário Oficial da União. Brasília, 22 dez. 2005.

BRASIL. Relatório do Grupo de Trabalho designado por Portaria Ministerial para elencar Subsídios à Política Linguística de Educação Bilíngue - Língua Brasileira de Sinais e Língua Portuguesa. Brasília: MEC/SEESP, 2014 BRASIL. Lei $\mathbf{n}^{\mathbf{0}} \mathbf{1 3 . 0 0 5}$, de 15 de junho de 2014. Aprova o Plano Nacional de Educação e dá outras providencias. 
CAMPELLO, Ana Regina de Souza. Pedagogia visual/sinal na educação dos surdos. Estudos Surdos II. Petrópolis, RJ: Arara Azul, p. 100-131, 2007.

CAMPELLO, A. R.; REZENDE, P. L. F. Em defesa da escola bilíngue para surdos: a história. Educar em Revista. Curitiba, Brasil, Edição Especial n. 2/2014, p. 71-92. Editora UFPR.

DA CUNHA PEREIRA, Maria Cristina. O ensino de português como segunda língua para surdos: princípios teóricos e metodológicos. Educar em Revista, n. Especial 2, p. 143-157, 2014.

FERNANDES, S. F. Educação bilíngue para surdos: identidades, diferenças, contradições e mistérios. Tese (Doutorado) - Universidade Federal do Paraná, Curitiba, 2003. Disponível em:

$<$ http://acervodigital.ufpr.br/bitstream/handle/1884/24287/T\%20-\%20FERNANDES, \% 20SUELI\%20DE\%20FATIMA\%20.pdf?sequence=1>. Acesso em: 27 ago. 2016.

FERNANDES, Sueli.; CERETTA MOREIRA, Laura. Desdobramentos políticopedagógicos do bilinguismo para surdos: reflexões e encaminhamentos. Revista Educação Especial. v. 22, n. 34, p. 225-236, maio/ago. Disponível em: http://www.scielo.br/pdf/er/nspe-2/05.pdf. Acesso em: janeiro/2016.

FERNANDES, Sueli.; CERETTA MOREIRA, Laura. Políticas de educação bilíngue para surdos: o contexto brasileiro. Educar em Revista, n. 2, 2014.

JESUS, Jefferson Diego de. Educação bilíngue para surdos: um estudo comparativo da escola bilíngue e do atendimento educacional especializado (AEE) na escola inclusiva. (Dissertação de Mestrado) Universidade Federal do Paraná, 2016.

LADD, Paddy. Understanding deaf culture: In: Search of Deafhood. British: Multilingual Matters Ltd, 2003.

LOPES, Maura Corcini. Surdez \& educação. Autêntica Editora, 2007.

MARTINS, Mônica Astuto Lopes. Relação professor surdo/alunos surdos em sala de aula: análise das práticas bilíngues e suas problematizações. Dissertação de Mestrado. UNIMEP, São Paulo, 2010

QUADROS, R. M de.; PERLIN, Gladis. Estudos surdos II. Petrópolis: Arara Azul, 2007.

QUADROS, Ronice Müller de. Educação de surdos: a aquisição da linguagem. Porto Alegre: Artes Medicas, 1997.

REIS, Flaviane. Professor surdo: A política e a poética da transgressão pedagógica. Dissertação (Mestrado em Educação) - Universidade Federal de Santa Catarina, 2006

RESENDE, Alice Almeida Chaves de.; LACERDA, Cristina Broglia Feitosa de. Mapeamento de alunos surdos matriculados na rede de ensino pública de um município de médio porte do Estado de São Paulo: dissonâncias. Rev. bras. educ. espec. [online], 
Educação bilíngue para surdos/as: um estudo comparativo da escola bilíngue e do atendimento educacional especializado (AEE) na

vol.19, n.3, p. 411-424, 2013.

REVISTA DA FENEIS. Federação Nacional de Educação e Integração dos Surdos. A Luta da Comunidade Surda Brasileira pelas Escolas Bilíngues para Surdos no Plano Nacional da Educação - PNE. Rio de Janeiro, julho de 2013.

SKLIAR, C. A localização política da educação bilíngue para surdos. In: SKLIAR, C. (Org.). Atualidade da educação bilíngue para surdos: interfaces entre pedagogia e linguística. Porto Alegre: Mediação, 1999. v. 2.

SKLIAR, C.B. Educação e exclusão: abordagem sócio-antropológica em educação especial. Porto Alegre: Mediação, 1997.

SVARTHOLM, Kristina. 35 anos de Educação Bilíngue de surdos-e então?. Educar em Revista, n. 2, 2014.

STÜRMER, Ingrid Ertel.; THOMA, Adriana da Silva. Políticas educacionais e linguísticas para surdos: discursos que produzem a educação bilíngue no brasil na atualidade. 37 ${ }^{\text {a }}$ Reunião Nacional da ANPEd - 04 a 08 de outubro de 2015, UFSC Florianópolis. Disponivel em: $<$ http://www.anped.org.br/sites/default/files/trabalhogt15-4093.pdf $>$. Acesso em: 28 ago. 2016.

VIEIRA, Claudia Regina. Educação de surdos: problematizando a questão bilíngue no contexto da escola inclusiva. 2011. Dissertação de Mestrado: Universidade Metodista de Piracicaba-UNIMEP.

\section{Como referenciar este artigo}

FERNANDES, Sueli.; JESUS, Jefferson Diego de. Educação bilíngue para surdos/as: um estudo comparativo da escola bilíngue e do atendimento educacional especializado (AEE) na escola inclusiva. Revista Ibero-Americana de Estudos em Educação, Araraquara, v. 12 , n. 3 , p. 1628-1648, jul./set. 2016. Disponível em: <http://dx.doi.org/10.21723/riaee.v12.n.3.2017.10355>. E-ISSN: 1982-5587.

Submetido em: 10/04/2017

Aprovação final em: 01/08/2017 